\title{
Infant Formula Promotion and Infant-Feeding Practices, Bicol Region, Philippines
}

\author{
Charles C. Griffin, PhD, Barry M. Popkin, PhD, and Deborah S. Spicer, MPh
}

\begin{abstract}
A 1978 household survey and a 1981 survey of stores and health facilities document the availability of breast milk substitutes, promotion of infant food and formula through the medical sector, and the effects of such promotion on the infant-feeding practices of mothers in the Bicol region of the Philippines. Breast milk substitutes were universally available in the region. Infant food and formula companies were active in the modern medical sector with promotional efforts that included distributing free formula
\end{abstract}

samples, providing pamphlets and posters, and organizing professional meetings. Industry activities had mixed effects on health professionals' knowledge of breast-feeding and attitudes towards the practice. Activities of multinationals tended not to affect mothers' breast-feeding behavior directly but increased the probability of their introducing breast milk substitutes within the first six months, and thus in practicing a program of mixed feeding. (Am J Public Health 1984; 74:992-997.)

\section{Introduction}

The advertising and promotional activities of infant food and formula companies are thought to operate in two distinct ways. ${ }^{1-3}$ First, some companies reach consumers directly through mass media advertising, home visits by milk nurses, distribution of promotional materials, and point-of-purchase marketing activities. Second, companies try to reach mothers indirectly by cultivating brand preference through contacts with and endorsements by health professionals. Activities aimed at the medical sector have included providing pamphlets, posters, and samples for distribution to clients; supporting professional conferences and seminars; paying expenses to professional meetings; furnishing equipment and supplies; and contributing to the construction of maternity wards. This article documents the availability of commercially produced breast milk substitutes, the extent of infant food and formula companies' promotional activities in the medical sector, and the effects of those activities on both health professionals and mothers in the Bicol region of the Philippines.

\section{Methods and Materials}

\section{The Bicol Region}

The analysis uses data collected in 1978 and 1981 in 100 randomly selected communities in the Bicol region. The Bicol region, consisting of four provinces located on Luzon Island (Camarines Sur, Albay, Sorsogon, and Camarines Norte) and two separate island provinces (Catanduanes and Masbate), is geographically the size of New Jersey and lies 300 kilometers southeast of Manila. About 83 per cent of the 3.47 million (1980 census) inhabitants are rural although the region is densely populated with almost 200 people per square kilometer. A railway line and an all-concrete highway run through the mainland to Manila, which is about 10 hours away by bus. Approximately 17 per cent of the dwellings were supplied with electricity in 1978, a level about average for the Philippines outside Manila.

The prominent Bicol economic activities are small-scale

Address reprint requests to Barry M. Popkin, PhD, Carolina Population Center, University of North Carolina, University Square 300A, Chapel Hill, NC 27514. Dr. Popkin is Associate Professor of Nutrition: Dr. Griffin is Research Associate: Ms. Spicer is formerly Research Assistant; all with the Carolina Population Center. This paper, submitted to the Journal October 11. 1983, was revised and accepted for publication February 15, 1984.

(C) 1984 American Journal of Public Health 0090-0036/84 \$1.50 farming and fishing, organized as family-owned businesses. Average 1975 family income was $\$ 535$ (at eight pesos to a dollar), making the region the third poorest among the 12 Philippine regions. Although few people attend school beyond the sixth grade, literacy levels are high, with 80 to 90 per cent of the population capable of reading.

\section{The Data}

The Philippines government and several international development agencies have begun the Bicol River Basin Development Program, a large integrated development project, which aims to raise living standards in Albay, Camarines Sur, and Sorsogon to the Philippine national average by 1990.

To evaluate the effects of this project, a baseline survey of 1,903 households in 100 barangays, ${ }^{*}$ drawn from a population of about two million people and 3,142 barangays in the three target provinces, was completed in 1978. The survey is representative of the household population in terms of both urban-rural location and household socioeconomic status. ${ }^{4}$ It is a compilation of socioeconomic, agricultural, and demographic data on these households, their 12,000 residents, and their communities. For this paper we used a subset of recall data on infant feeding practices which is explained in more detail below.

In 1981, the Carolina Population Center commissioned the Ateneo de Naga Research and Service Center to return to the 1978 sample barangays to survey health facilities and stores selling infant food products. The sample consisted of 518 government, private, and traditional medical facilities (or individual practitioners) and 73 stores. Heads of medical facilities were asked about the availability and prices of outpatient, prenatal, and obstetrical care; their infant formula and food sample distribution policies; and their contacts with the industry. Each of the 73 stores represented the one most commonly used by barangay residents. There are fewer than 100 stores because some served more than one sample barangay. Field investigators inventoried the brands and prices of breast milk substitutes available in these stores.
*The Philippines are divided into 12 regions which are partitioned into provinces and chartered cities. Each province is divided into municipalities which are subdivided into barangays containing 1,000 to 2,000 people each. The main town is usually the administrative center of the municipality and is called a poblacion. Chartered cities, which are independent of provincial governments, are also divided into barangays. There are a total of about 40,000 barangays in the Philippines. 
TABLE 1-Accessibility of Stores Serving the 100 Sample Barangays, Bicol Region, Philippines, 1981'

\begin{tabular}{lcc}
\hline \multicolumn{1}{c}{ Accessibility Measures } & $\begin{array}{c}\text { Urban } \\
\text { Barangays }\end{array}$ & $\begin{array}{c}\text { Rural } \\
\text { Barangays }\end{array}$ \\
\hline Number of barangays in each category & 31 & 69 \\
Average distance, barangay to store $(\mathrm{km})$ & 3.5 & 8.8 \\
Average transport cost (pesos, one-way) & .58 & 1.53 \\
Average transport time (minutes, one-way) & 11.6 & 37.5 \\
\hline
\end{tabular}

SOURCE: BMSS81 (see Acknowledgments)

${ }^{1} A$ total of 73 stores serving the 100 sample barangays were surveyed. This Table is based on barangays and not stores, so some stores are counted more than once. For example, if store A served both barangay 1 and barangay 2 it would be counted twice. The point of the Table is not to describe store characteristics but to describe the accessibility of stores to the sample barangays.

2Urban includes barangays in Naga City, Legaspi City, Iriga City and poblacions (towns).

${ }^{3} \mathrm{At}$ the time of this survey, peso $7.35=$ U.S. $\$ 1.00$. There are 100 centavos to a peso.

\section{Results}

Availability of Breast Milk Substitutes through Stores

Table 1 contains barangay-based statistics describing the accessibility of stores to the sample barangays. Rural barangays were an average of about twice as far as urban barangays from the stores serving them. Transport cost and time to market in the countryside were about triple the urban costs.

About 90 per cent of the communities were served by stores which had at least one brand of powdered infant formula on the shelves (see Table 2). All stores which did not sell formula had other potential breast milk substitutes, such as powdered milk or sweetened condensed milk, on the shelves. Whole milk is generally not sold in the Philippines; powdered milk products are widely available and commonly used. Rural residents in the Bicol region appear to have as much choice of brands, at similar prices, as do urban residents.

Stocking a product does not in itself constitute promotion, although availability is a prerequisite to mothers'

TABLE 2-Availability and Cost of Breast Milk Substitutes to 100 Sample Barangays, Bicol Region, Philippines, 1981

\begin{tabular}{lccc}
\hline \multicolumn{1}{c}{$\begin{array}{c}\text { Breast Milk } \\
\text { Substitutes }\end{array}$} & $\begin{array}{c}\text { \% Barangays } \\
\text { with Item } \\
\text { Available }\end{array}$ & $\begin{array}{c}\text { Average No. } \\
\text { Brands Available } \\
\text { to Barangay }\end{array}$ & $\begin{array}{c}\text { Average Price } \\
\text { of Available } \\
\text { Brands }\end{array}$ \\
\hline $\begin{array}{l}\text { Formula } \\
\text { Powdered Milk }\end{array}$ & 94 & 6.8 & $3.90^{2}$ \\
$\begin{array}{l}\text { Evaporated Milk } \\
\begin{array}{l}\text { Sweetened } \\
\text { Condensed Milk }\end{array}\end{array}$ & 96 & 4.4 & $3.45^{2}$ \\
& 96 & 3.5 & $23.16^{3}$ \\
$\begin{array}{l}\text { Formula } \\
\text { Powdered Milk }\end{array}$ & 88 & 3.9 & $32.52^{3}$ \\
$\begin{array}{l}\text { Evaporated Milk } \\
\text { Sweetened } \\
\text { Condensed Milk }\end{array}$ & 93 & Rural & $3.85^{2}$ \\
\hline
\end{tabular}

SOURCE: BMSS81 (see Acknowledgments)

1 Prices quoted in pesos with a conversion rate at the time of the survey of peso $7.35=$ U.S. $\$ 1.00$.

${ }^{2}$ Centavos/gram (powdered)

${ }^{3}$ Centavos/ounce (liquid). purchasing the items, and putting products on shelves may set up indirect demonstration effects. Additional data on specific marketing practices, such as point-of-purchase coupons, counter displays, promotional campaigns, and sample distribution, are necessary to measure the active promotion of these products to consumers at the point of sale.

\section{Promotion through Health Facilities}

Of the 518 health facilities surveyed in 1981, 101 offices of herbal doctors were eliminated from this analysis because they usually do not treat healthy pregnant women. The remaining 417 facilities include offices of both modern practitioners and traditional midwives (see Table 3 ).

Before discussing the data, we must make a distinction between formula supplies and formula samples. Formula companies often supply free formula to hospitals for feeding infants in the nursery. Some companies also set up "milk banks" at hospitals where formula-feeding mothers can get company brands at reduced prices. The latter practice is certainly promotional in nature, and increases the possibility that breast-fed babies will receive formula supplementally, especially in hospitals. However, such practices are brandoriented and appear to be aimed at mothers who already use formula.

The indiscriminate distribution of formula samples to breast-feeding mothers at discharge is an entirely different practice, however, which may either intentionally or unintentionally convert into formula users mothers who would otherwise have breast-fed. In asking about formula samples, we therefore inquired specifically about the latter practice: the heads of facilities were asked whether they were given free samples of breast milk substitutes for distribution to mothers, how often the samples were received, and whether the samples were actually distributed.

Table 3 shows that virtually no facilities received powdered milk samples, that infant food samples were distributed primarily to private clinics and hospitals, but that formula samples were widely distributed in the modern sector to health facilities. Of those practitioners and facilities receiving formula samples, 55 per cent received them regularly and 84 per cent distributed them either all or some of the time. Tallies by company show that the few traditional midwives getting free formula samples received them primarily from Wyeth. Nestlé, Wyeth, and Mead Johnson had brands available in the majority of both government and private clinics and hospitals.

Interviewers asked to see all donated equipment or supplies in the clinics, including printed material. Equipment was donated by both government and private organizations; for example, 32 per cent of the traditional midwives had received delivery kits from a private nonprofit organization. Sources of donations other than infant food and formula companies included government agencies, pharmaceutical companies, and drug distributors. Nevertheless, 25 per cent of the tape measures, 95 per cent of the identification bracelets, 41 per cent of the growth charts, 24 per cent of the prescription pads, and 21 per cent of the pens and pencils came from infant food or formula companies. Nestlé and Wyeth were the most active in this regard.

Posters and pamphlets were present in almost every modern facility. Government agencies, Nestlé, and Mead Johnson were the major suppliers, with posters and pamphlets from some industry source present in from 33 to 80 per cent of the modern facilities. Because we lack information on the content of these materials, this evidence on printed 
TABLE 3-Per Cent of Health Facilities Having Samples of Breast Milk Substitutes, by Type of Facility and Supplier, Bicol Region, Philippines, 1981

\begin{tabular}{|c|c|c|c|c|c|c|c|}
\hline & $\begin{array}{l}\text { Traditional } \\
\text { Midwife } \\
\text { Office }\end{array}$ & $\begin{array}{l}\text { Private } \\
\text { Nurse/Midwife } \\
\text { Office }\end{array}$ & $\begin{array}{l}\text { Government } \\
\text { Clinic }\end{array}$ & $\begin{array}{l}\text { Private } \\
\text { Clinic }\end{array}$ & $\begin{array}{l}\text { Government } \\
\text { Hospital }\end{array}$ & $\begin{array}{l}\text { Private } \\
\text { Hospital }\end{array}$ & Total \\
\hline Number of Facilities by Type & 194 & 46 & 59 & 63 & 15 & 40 & 417 \\
\hline \multicolumn{8}{|l|}{$\begin{array}{l}\text { Percentage of Health Facilities Receiving Free Milk/Food } \\
\text { Samples }\end{array}$} \\
\hline Powdered Milk & 0 & 0 & 3 & 3 & 0 & 5 & 1 \\
\hline Formula & 5 & 33 & 70 & 73 & 67 & 95 & 38 \\
\hline Infant Foods & 0 & 9 & 19 & 40 & 20 & 63 & 16 \\
\hline \multicolumn{8}{|l|}{$\begin{array}{l}\text { Percentage of Facilities Receiving Formula Samples, by } \\
\text { Supplier }\end{array}$} \\
\hline Nestlé & 1 & 26 & 66 & 62 & 60 & 85 & 32 \\
\hline Mead Johnson & 1 & 26 & 37 & 51 & 47 & 70 & 24 \\
\hline Wyeth & 4 & 26 & 61 & 52 & 47 & 63 & 30 \\
\hline Abbott & 0 & 0 & 0 & 3 & 0 & 3 & 1 \\
\hline \multirow{2}{*}{\multicolumn{8}{|c|}{$\begin{array}{l}\text { Percentage of Facilities Allowing Contacts between } \\
\text { Company Representatives and Mothers or Giving Out } \\
\text { Client Names }\end{array}$}} \\
\hline & & & 25 & 8 & 20 & 28 & 11 \\
\hline
\end{tabular}

SOURCE: BMSS81 (see Acknowledgments).

materials is more an indicator of promotional contacts between the industry and the medical sector than a measure of formula or food promotion to mothers, which would require additional data on content.

Heads of facilities were asked whether representatives of infant food or formula companies were allowed to talk to clients attending the clinic of if clients' names were given out to representatives. From 8 to 30 per cent of government and private facilities gave industry representatives access to clients (see Table 3). For those facilities allowing this practice in 1981, Nestlé had access in 68 per cent, Mead Johnson in 23 per cent, and Wyeth in 18 per cent. Carnation and Abbott had access in less than 1 per cent. Despite the fact that about one-fourth of modern facilities allowed industry-mother contacts, the predominance of traditional home deliveries (only 8 per cent of the 1978 sample delivered in hospitals or health clinics) is consistent with a low level of actual contacts between industry representatives and mothers ( 3 per cent) found in the 1978 household survey.

\section{Health Professionals}

The 1981 medical facility survey also interviewed a subsample of 1,298 government, private, and traditional health professionals serving pregnant women in the 100 survey communities. Of those interviewed, 52 per cent had been contacted in the past year by a representative of an infant formula company. Approximately 23 per cent had attended an industry-sponsored conference during their careers, and 5 per cent reported that an infant food or formula company had paid their expenses for a professional meeting in the past two years. Of the health professionals attending an industry-sponsored conference, 71 per cent reported Mead Johnson, and 31 per cent reported Nestlé as the sponsor or cosponsor.

Health professionals were tested for their knowledge of the benefits of breast-feeding, the psychophysiology of lactation, contraindications to breast-feeding, and the effects of drugs and contraceptives on lactation. ${ }^{5}$ They were also scored for their attitudes toward breast-feeding based on the content of their usual conversations with mothers about infant feeding, the importance they place on breast-feeding, and their advice to working mothers who want to breastfeed. The mean scores on the knowledge and attitude tests were 55 per cent and 78 per cent, respectively.

We tested the effects of sex, position, government training programs, work experience, age, and contacts with the infant food industry on these scores. Complete sets of coefficient estimates for the regressions are available from the authors; in this presentation we concentrate on only the most important findings, all of which were statistically significant at the 5 per cent level.

Traditional midwives achieved significantly lower scores than other health workers on both the knowledge and attitudes tests. This finding contradicts the usual assumption that traditional birth attendants are more supportive of breast-feeding than their modern counterparts and suggests the hypothesis that traditional midwives reflect thinking and habits common to their culture rather than using independently acquired knowledge to guide patients 'infant-feeding practices.

The results for industry and governmental contacts were mostly counterintuitive but appear in hindsight to be logical. Attendance at an industry-sponsored conference in which infant feeding was discussed was associated with a reduction in the knowledge score, while attendance at an industry-sponsored conference covering other topics was associated with an increase in both knowledge and attitude scores. Neither talking to an industry representative nor having conference expenses paid by the industry was a statistically significant predictor of the knowledge score. In comparison, attendance at government-sponsored primary health care training programs was associated with reduced knowledge scores, but maternal and child health training was associated with improved scores. These data suggest that the identity of the sponsor is less important than the content of the conference or training program in determining knowledge and attitudes.

\section{Effects of Industry and Health Professionals on Infant-Feeding Behavior}

Of the 1,903 households covered in the 1978 Bicol Multipurpose Survey, 632 contained at least one child under 24 months of age. In testing the effect of industry and health professional contacts on mothers' infant-feeding decisions, our sample consisted of these 632 open interval, or youngest, children. Previous work in this area has concentrated on the 


\begin{tabular}{|c|c|c|c|c|c|}
\hline \multirow[b]{2}{*}{ Feeding Methods } & \multicolumn{5}{|c|}{ Infant's Age } \\
\hline & Birth & 3 Months & 6 Months & 9 Months & 12 Months \\
\hline $\begin{array}{l}\text { Number of infants old enough to be included } \\
\text { in the sample at each age interval } \\
\text { Per cent of sample breast-fed } \\
\text { Per cent of sample fed breast milk substitutes } \\
\text { Per cent of sample fed supplemental foods }\end{array}$ & $\begin{array}{r}618^{3} \\
92.6 \\
7.4 \\
0.0\end{array}$ & $\begin{array}{r}551 \\
88.0 \\
32.3 \\
12.7\end{array}$ & $\begin{array}{c}472 \\
84.1 \\
42.8 \\
57.6\end{array}$ & $\begin{array}{r}387 \\
79.8 \\
53.7 \\
89.1\end{array}$ & $\begin{array}{r}312 \\
74.0 \\
61.9 \\
97.1\end{array}$ \\
\hline \multicolumn{6}{|c|}{$\begin{array}{l}\text { SOURCE: BMS78 (see Acknowledgment). } \\
\text { 1These data depend on recall responses. } \\
\text { 2Because mothers were asked about the youngest child, in one household this might be a baby } 1 \text { month old and in another it might } \\
\text { a child } 15 \text { months old. For the } 1 \text {-month old child, we would have the feeding choice at birth only, and it would be eliminated from the } \\
\text { nples at } 3 \text { months of age and above. In contrast, the } 15 \text {-month old child would appear in the sample at birth, } 3 \text { months, } 6 \text { months, } 9 \\
\text { nths, and } 12 \text { months. }\end{array}$} \\
\hline
\end{tabular}

ever/never breast-feeding decision and the duration of total breast-feeding. Our approach, in contrast, models the entire range of feeding choices facing mothers: breast-feeding, feeding breast milk substitutes, and introducing solid foods. Table 4 contains sample statistics describing feeding choices for this sample. Almost 93 per cent of the babies had been breast-fed at birth, and 74 per cent were still being breast-fed at one year. Sixty-two per cent of those children at least a year old had also been fed formula, evaporated milk, or some other type of breast milk substitute by the end of their first year. By the third month, 12 per cent of the infants were being fed supplemental foods. By the end of one year, nearly all were getting solid foods.

Table 5 contains estimated coefficients for five sets of logit regressions explaining infant feeding decisions for the 1978 Bicol sample at birth and every three months thereafter through the first year of life. The underlying economic model and a full explanation of our methods appear elsewhere;** for this analysis, we will discuss the results for variables measuring industry and health professional contacts with mothers.

Under industry variables we include the price of infant formula, whether formula is available from the local store, and distance to the store. Promotional activities are measured by whether the mother was given free samples at delivery and whether the local health facility or practitioner of the type the mother used distributed free samples in 1981. For health professionals, we include the general knowledge and attitude scores for the practitioner or facility the mother is likely to have used for delivery. For each age interval we estimated the probability of breast-feeding (B), feeding breast milk substitutes (M), and feeding supplemental foods (S). The technique used is a variation of the loglinear model, a seemingly unrelated regression with qualitative dependent variables. ${ }^{6}$ This estimation technique provides estimates of the covariance among the three feeding techniques, reported at the bottom of the Table.

We expected that higher formula prices would increase the probability of breast-feeding and reduce the probability of using breast milk substitutes at each time interval. This effect did not occur. Similarly, women living in communities where formula is not available in the local store should be

**Akin JS, Griffin CC, Guilkey DK, Popkin BM: Determinants of infant feeding: A household production approach. Chapel Hill: Carolina Population Center, University of North Carolina at Chapel Hill, 1983. less likely to use breast milk substitutes. This effect also did not occur. In fact, having infant formula in the local store actually increased the probability of breast-feeding at 3 months, a highly counterintuitive result.

Distance to the store, however, was an important determinant of infant-feeding behavior. The farther away was the store, the more likely the woman was to breast-feed initially and to continue it through the third month. For the decision to feed breast milk substitutes, while only one of the distance coefficients was statistically significant, the signs consistently suggest that distance has a deterrent effect on using breast milk substitutes. In other words, the harder it is to get to a store selling commercially produced breast milk substitutes, the more likely the woman is to breast-feed and the less likely she is to feed substitutes.

If this distance effect is considered in combination with the counterintuitive results for formula price and availability, it appears that the major economic factor affecting the choice of feeding technique is accessibility, not the cost or availability of formula. An obvious hypothesis to be tested when more detailed data become available is whether the identity of products on store shelves is less important for infant-feeding decisions than the distance between the mother and the store.

Our two formula promotion variables require careful interpretation. One variable directly measures whether the mother received a free formula sample at delivery. This variable showed no statistically significant impact on the initial breast-feeding decision and had a surprising, positive effect on the probability of breast-feeding at three months. It also had a significant positive effect on the probability of introducing breast milk substitutes at three, six, and nine months. In other words, receiving formula samples increased the probability of introducing breast milk substitutes after three months but had no effect on the initial breastfeeding decision and a positive effect on the probability of breast-feeding at three months.

Our second measure of promotion captures a community-level demonstration effect of sample distribution policies. It equals 1 if the local health professional or facility of the type the mother used for delivery distributed free samples in 1981 and 0 otherwise. This facility-level sample distribution variable had three statistically significant effects. A woman exposed to a facility distributing formula samples was less likely to breast-feed initially and more likely to introduce breast milk substitutes at both 9 and 12 months. The 
important effect is the initial one reducing the probability of ever breast-feeding. If the average baby were taken from an area where health facilities did not distribute free formula samples to one where samples were distributed, there would be a .061 drop in the probability of its being breast-fed at birth, other things constant (instead of a 96 per cent chance of being breast-fed at birth, it would have a 90 per cent chance). We must be cautious in interpreting the causality of this variable. Because the mother's actual receipt of samples at her infant's birth was controlled for in the analysis, this reduction in the probability of breast-feeding may relate to characteristics of mothers who chose facilities providing samples or to other practices which occur at such facilities.

Health professionals' knowledge of lactation and attitudes toward breast-feeding appeared to have no systematic effect on the infant-feeding behavior of the women in this sample. A higher knowledge score, for example, had a positive effect on the probability of introducing substitutes by three months. Proper evaluation of health professionals' impact on feeding practices requires knowledge of specific advice mothers get and when they get it. Therefore, our finding of no systematic effect requires additional supporting evidence using longitudinal data.

The coefficients measuring covariation among the feeding methods were large and statistically significant. Breastfeeding and feeding breast milk substitutes were negatively related in all age intervals: supplementation and feeding breast milk substitutes were positively related in all age intervals; and supplementation and breast-feeding became positively related after the sixth month. ${ }^{* * *}$

\section{Discussion}

We have documented the universal availability of breast milk substitutes and the active role played by the infant formula and food industries in the medical sector in the lowincome Bicol region of the Philippines. We found that distance to a store, not availability of formula on the shelves, was the most important economic factor affecting the probability of breast-feeding. Food industry contacts with the medical sector had no clearcut pattern of negative effects on health professionals' knowledge of breast-feeding or their attitudes toward the practice.

The current policy debate emphasizes the marketing practices of multinationals, the presence of multinationals in the medical sector, and the power of health professionals over the feeding behavior of mothers. As usual, trying to bring hard evidence to bear on these issues shows first and foremost that they are probably much more complicated than previously thought. The analysis does suggest plausible answers to several important questions.

- First, what would be the effect of removing formula from stores? Our work suggests that this policy would not positively affect breast-feeding behavior. Women in our sample appeared to be deterred from using breast-feeding alternatives by distance to a store but were not deterred

${ }^{* * *}$ As an important methodological aside, we compared our approach with the traditional single equation analysis of the breast-feeding decision and found significant differences from the breast-feeding results reported in Table 5. Assuming our model is correct and these infant feeding decisions are jointly determined, analysis of the breast-feeding decision separately (omitting these covariance terms) results in the use of the wrong variance-covariance matrix. the calculation of incorrect asymptotic t-statistics, and potentially biased coefficients. We found nine overall sign changes and six changes in the statistical significance of coefficients (either becoming significant or losing significance). (See earlier footnote ${ }^{* *}$ Akin et al.) either by the price or the identity of what was on the shelves. Women in our sample who used breast milk substitutes were also more likely to introduce supplemental foods earlier. Consequently, policies restricting formula sales should be preceded by analysis which verifies whether formula will be replaced by breast milk of if a loss of the formula option will result not in more breast-feeding but simply in a greater dependence on semisolid foods and other liquids.

- Second, what would be the effect of restricting contacts between the medical and formula sectors? It would definitely reduce the amount of equipment, supplies, and informational material available to modern sector professionals in our sample. It would have almost no effect on traditional midwives, who attended 65 per cent of the deliveries in the Bicol region in 1978 and who performed much worse than modern health professionals on the breastfeeding knowledge and attitude tests. It would reduce the number of conferences attended by health professionals but would not necessarily improve either their knowledge or attitudes about breast-feeding. Our evidence suggests that improving health professionals' knowledge of breast-feeding-whether accomplished by industry, government, or both-is probably the most important area of concern.

- Third, what would happen ifformula sample distribution to mothers were curbed or eliminated? Our estimations indicate that such a policy would slightly increase the probability of breast-feeding at birth and at three months, and would reduce the probability of introducing breast milk substitutes after the third month. Restricting formula sample distribution would therefore have its strongest effect in reducing the incidence of mixed feeding. To the extent that early feeding of breast milk substitutes is related to later reductions in the probability of breast-feeding, this policy could have a long-run, indirectly positive effect on the probability of continuing breast-feeding. ${ }^{3}$

\section{REFERENCES}

1. World Health Organization: Contemporary Patterns of Breast-feeding. Report on the WHO Collaborative Study on Breast-feeding. Geneva: WHO, 1981.

2. Greiner T: The Promotion of Bottle Feeding by Multinational Corporations: How Advertising and the Health Professions Have Contributed. Cornell International Monograph Series, No. 2. Ithaca, NY: Cornell University, 1975.

3. Popkin BM, Bilsborrow RD, Akin JS, et al: Breast-feeding determinants in low-income countries. Medical Anthropology 1983; 7:1-31.

4. Popkin BM, Roco S Jr, with Bragais P Jr, Callison CS: Bicol Multipurpose Survey 1978. Vol 1. Survey Design and Implications. Manila: Agency for International Development, 1981.

5. Popkin BM. Yamamoto MC, Griffin CC: Traditional and modern health professionals and breast-feeding. J Pediatr Gastroenter Nutr.

6. Schmidt P, Strauss RP: The prediction of occupation using multiple logit models. Int Econ Rev 1975: 16:471-486.

\section{ACKNOWLEDGMENTS}

We thank the Bicol River Basin Development Program: the Agency for International Development. Philippines: and the Research and Service Center (RSC), Ateneo de Naga, for making available the 1978 Bicol Multipurpose Survey (BMS78) data tapes. We also thank the RSC for collaborating with the Carolina Population Center (CPC). University of North Carolina at Chapel Hill, in conducting the 1981 Bicol Multipurpose Supplemental Community Survey (BMSS81). CPC funded the collecting and processing of BMSS81 data with a primary health care research grant from the Program and Policy Coordination Bureau of the Agency for International Development and supplemental grants from the Nestlé Coordination Center for Nutrition and from Ross Laboratories. Additional analysis support has come from CPC, the UNC Department of Nutrition, and Ross Laboratories. We also thank Dr. Florentino S. Solon, Director. Nutrition Center of the Philippines, for assisting us in obtaining the 1981 health facility interviews. 